\title{
Can Microalgae Act as Source of Preservatives in Food
}

\section{Chain?}

\author{
Priscila Tessmer Scaglioni and Eliana Badiale-Furlong \\ School of Chemistry and Food, Laboratory of Food Science and Mycotoxins, Federal University of Rio Grande (FURG), Rio Grande \\ 96203-900, RS, Brazil
}

\begin{abstract}
Microalgae are a potential source for various valuable chemicals for commercial applications ranging from nutraceuticals to fuels. This review aims to focus on microalgal as preservative potential to food chain. The main compounds responsible for these properties, like carotenoids, phenolic compounds, antioxidant vitamins, sterols and polyunsaturated fatty acids are discussed because microalgae can be cultivated under controlled conditions to improve their production. We have listed several studies performed in recent years supporting the health benefits that most of these compounds can provide. Therefore, they may represent an excellent source of preservatives in food chain once their safety as a food supplement has been also confirmed.
\end{abstract}

Key words: Antimicrobial, antioxidant, bio-compounds, natural preservatives.

\section{Introduction}

Antimicrobials are natural (antibiotic) or synthetic substances (chemotherapeutic agents) that act on microorganisms by inhibiting their growth or causing its destruction, therefore they are classified as preservatives [1]. However the synthetic one has been associated to hazard to human, animal and others species and also environment.

There is a strong debate about the safety of chemical preservatives, since they are considered responsible for many carcinogenic and teratogenic attributes, as well as residual toxicity [2]. They are ingested with the food, therefore safety measures to prevent risks to public health are necessary. To this end, Codex Alimentarius establishes, for most food additives, the so-called acceptable daily intake, which essentially means the maximum amount of preservative that can be ingested daily.

Beside this it has been observed an increasing interest in natural compounds that could replace the synthetics ones in pharmaceutics and food industries, intending to provide alternatives to adverse effects of

Corresponding author: Priscila Tessmer Scaglioni, doctor, research field: natural compounds with antifungal activity. them on the health, ecological chains, and environment.

The antimicrobial substances that include unsaturated lactones, cyanogenic glycosides, sulphur containing compounds, phenols and phenolic glycosides, saponins and phytoalexins [3-5] are among compounds that have been explored from plants although they are also present in microalgae. However it would be better to understand them before applying in scale up for pharmaceutical, food and other industries.

More than sixty trace elements such as minerals, proteins, iodine, bromine and bioactive substances have been found in microorganisms [6]. To date, many chemically unique compounds of fresh water origin with various biological activities have been isolated. Some of them are under investigation and others are being used to develop new pharmaceuticals and food products [7-10] therefore they are commercially important living and renewable resource for compounds with biological activity.

In special the synthetic antifungals are widely used as a preventive measure for fungal contamination in field, on processed foods and medicine. However they 
can be found as residual in environmental and agricultural products because their application does not always result in efficient performance. Some of them can cause fungal stress and the consequence is mycotoxins production $[11,12]$. Also fungicides may alter metabolic reaction in plants once they are systemic. Among the alternatives widely studied for the problem is the search for natural compounds, of microbial or vegetal origin, with demonstrated antifungal potential [13].

This critical review provides an overview of the state of the art on the properties of microalgae as preservatives, focuses on use of the extractable compounds of them, and the advantages of this biotechnology and its limitations to food chain application.

\section{Natural Preservatives}

Antioxidants present in plants, algae and mushrooms are excellent natural source of functional compounds for human diet and some of them may act as additives in industrial chains therefore they have been presented as alternatives to synthetic additives. Vitamins, polyphenols and carotenoids are considered the most natural antioxidant molecules [14-17]. Due to their high antioxidant power, the polyphenols are considered among the most interesting and relevant natural compounds to be used as food preservatives and bioactive ingredients in medicine, crops treatment, food and feed formulation and food package [4, 18, 19].

The natural antimicrobials are yielded by animal, vegetal and microbial origin, as defense against pathogens by causing inefficiency or making them unviable. Some compounds with antimicrobial properties are able to promote protection against physical and chemical effects also because this reinforces the defense against pathogens.

Antimicrobial agents from animal are mainly polypeptides that can be activated by enzymatic hydrolysis, releasing biologically active peptides [20].
Some examples of antimicrobial peptides from animal origin can be used as food additives such as: lactoferrin [21], bovine casein peptides [22], chitosan [23], and pleurodynia [24].

Since the earliest historical records, vegetables extracts from aromatic plants have been used for different purposes in food, medicine and cosmetics. The essential oils, in addition to presenting antioxidant and anti-inflammatory activity are considered the most important antimicrobial agents present in plants [25]. The cytotoxic activity of essential oils is attributed to phenolic compounds, aldehydes, terpenes, aliphatic alcohols, ketones, acids and isoflavonoids. The phenolic components are cited as the main chemicals responsible for the antibacterial properties of these oils, however there are reports that non-phenolic compounds, such as allyl isothiocyanate, are more effective than the ones Gram negative bacteria, as well have being shown effective against fungi [26].

Antimicrobials of bacterial origin are represented mainly by peptides synthesized via ribosomes. They are called bacteriocins and have been applied in foods susceptible to microalgal degradation aiming to promote food security [27]. The knowledge about bacterial fermentations is used for millennia, not only for development of food products with a peculiar flavor, but also to extend their shelf life, mainly by lactose conversion to lactic acid [28]. In addition, other products of bacterial metabolism, including hydrogen peroxide, acetoin, diacetyl, other organic acids and bacteriocins act as bio-preservatives, by altering intrinsic properties of foods, in such a way that they inhibit the growth of microorganisms [29].

The bacteriocins produced by acidolytics bacteria have been motivating the food industry because they offer various properties suitable for food preservation. They are Generally Recognized As Safe (GRAS), thermotolerant, presenting activity in a wide range of $\mathrm{pH}$, with broad spectrum of action against several microbial species. However, they have little influence 
on the intestinal microbiota, being inactivated by digestive proteases [30]. The most important are: nisin [31], pediocin [32] and reuterin [33].

The naturally occurring antifungal compounds also act in the fungal and mycotoxigenic inhibition by affecting different defense mechanisms of the microorganism metabolism. Phenolic compounds, proteins, essential oils, among others, can act inhibiting cell wall components such as glycosamine, chitin, ergosterol and mannoproteins, destroying the membrane integrity and hindering the entry of nutrients $[4,34,35]$. They can also inhibit protein and amino acids synthesis, biosynthesis of sphingolipids to interfere in the transport of electrons, making the fungal cell integrity unfeasible [36].

The antifungal activity is determined by comparison between microorganism biomass with and without fungicides in the media. The measurement of colonies halo inhibition, constituents of membranes and cell walls (ergosterol and glucosamine), alterations in the enzymatic activity with consequent diminution of the synthesis of biomolecules of the species, are the indicatives used to demonstrate inhibition mechanism of cellular growth [11, 35, 37].

The use of glycosamine as a measure of fungal biomass is based on the quantification of a major constituent of the fungal cell wall, chitin, a linear insoluble polymer composed of acetylglucosamine $\alpha-1,4$ bonds. The determination consists of the depolymerization of the chitin molecule, followed by the spectrophotometric assay of the amount of glycosamine released [38].

Ergosterol is a good indicator of fungal development due to its correlation with the metabolically active biomass. Its determination allows verifying changes during fungal growth [39]. Therefore ergosterol is a promising indicator of fungal development because it is specific steroid of this microorganism genus [40].

They can be used alone or combined with other technology. However, the choice of antimicrobial agent should be based on its chemical and sensory compatibility with the target food, its effectiveness against undesirable microorganisms, safety, among other characteristics [30].

Therefore it is a challenge to find microorganisms that yield biomass efficiently under controlled conditions and beside produced compounds biologically active that they allow manipulation.

\section{Microalgae Biomass}

The majority of marine microorganisms do not grow on the nutrient-rich agar medium commonly used for isolation and microorganism cultivation. This may be related to the artificial conditions used in culture media, including the lack of specific nutrients required for growth or the absence of positive microbial interactions [41]. Innovative cultivation methods are also required to improve the exploitation of the biomass derived from marine microalgae that represents a great but still underexplored source of valuable chemical constituents to promote health and reduce the risk of the development of degenerative diseases [42].

Aquatic organisms produce primary and secondary biologically active, chemical that may be interesting for the pharmaceutical and food industries [43]. In this context, microalgae, microscopic photosynthetic organisms that are found in marine and fresh water have attracted attention.

Microalgae are a diverse group of prokaryotic and eukaryotic photosynthetic microorganisms with a unicellular or simple multicellular structure that allows them to grow rapidly and live in extreme conditions [44]. Due to this simple structure, they harness solar energy more quick and efficient through photosynthesis, than the crop plant [45].

More than 100,000 different species of microalgae exist around the world, but no more than 30,000 have been investigated and classified, according to their color, size, pigments, cell wall constituencies or other [46-48]. 


\subsection{Cultivation}

Cultive of microalgae biomass can be performed by autotrophic, heterotrophic, mixotrophic and photoheterotrophic processes. Autotrophic culture needs light as a source of energy and inorganic carbon $\left(\mathrm{CO}_{2}\right.$, for example) for yielding chemical energy through photosynthesis [49]. Heterotrophic cultivation is performed when the microalgae species uses organic carbon as source of energy [50]. Mixotrophic occurs when the microalga, under photosynthesis, uses as organic carbon and $\mathrm{CO}_{2}$ for growing [51]. Photoheterotrophic cultivation requires light and microalgae need organic compounds as source of carbon [52].

Photobioreactors used for microalgae cultivation can be classified into two main types: open systems (high-rate aerated tanks with elliptical ends, raceway ponds, lakes, etc.), and closed systems (tubular, plate reactor, conical, pyramidal, fermenter, etc.) [53].

Closed photobioreactor systems are the most suitable for microalgae that can be rapidly contaminated by other microorganisms, except for microalgae that can survive in extreme environmental conditions such as high $\mathrm{pH}$ (Spirulina, for example) and high salinity (Dunaliella, for example ) or can grow very quickly (Chlorella, for example) in open tanks [54].

The wastewater, after previous treatment (physical and/or chemical) can be used only or as an additive to microalgae cultivation $[55,56]$. Furthermore, wastewater can be used for microalgae cultivation in open or closed systems because it contains abundant nutrients (sources of nitrogen, phosphorus, carbon, among others), which are necessary for microalgae biomass production.

Table 1 shows the main advantages and disadvantages of the two types of microalgae cultures that have been demonstrated by different authors in recent years.

Temperature is one of the most important parameters for all metabolic processes. Cultivation at higher temperatures generally increases biomass production and consequently protein, lipid, and total compound production, including secondary metabolites [57]. To control $\mathrm{pH}$ is useful in order to prevent contamination by microorganisms and to assess the effective nutrient absorption from the culture medium [58]. Photosynthetic microalgae are influenced by light that affects biochemical composition of biomass, especially in terms of fatty acids and antioxidants. Studies have been demonstrated that salinity stress can also influence secondary metabolites productions, in particular antioxidants. As an example, the addition of $\mathrm{NaCl}$ promoted synthesis of free and ester-type xanthophylls due to higher light and salt stresses that synergistically activated carotenogenesis in the algal cells [59].

Table 1 Advantages and disadvantages of open and closed systems in microalgae cultivation.

\begin{tabular}{|l|l|l|l|}
\hline & Open systems & Closed systems & Reference \\
\hline Advantages & $\begin{array}{l}\text { Simplicity; } \\
\text { Lower construction, operating and production } \\
\text { costs; } \\
\text { Possibility to work with high amounts of } \mathrm{CO}_{2} .\end{array}$ & $\begin{array}{l}\text { Natural source of light variability } \\
\text { is eliminated; } \\
\text { Good process control; } \\
\text { Obtaining high cell density. }\end{array}$ & [45, 60-62] \\
\hline Disadvantages & $\begin{array}{l}\text { Slow (light limitation imposed by high cell } \\
\text { density or due to photoinhibition caused by } \\
\text { excess light); } \\
\text { Microalgae can be contaminated by external } \\
\text { species; } \\
\text { Low cell density and expensive harvesting } \\
\text { process; } \\
\text { Exposed to weather fluctuations, which causes } \\
\text { evaporation under high temperatures; } \\
\text { Biomass dilution under rains. }\end{array}$ & $\begin{array}{l}\text { Overheating; } \\
\text { Biofouling; } \\
\text { Oxygen accumulation; } \\
\text { Difficulty of enlargement; } \\
\text { High construction, operation and } \\
\text { cultivation costs; } \\
\text { Damage to cells by shear stress; } \\
\text { Material deterioration by } \\
\text { luminous phase. }\end{array}$ & [46, 54, 63-65] \\
\hline
\end{tabular}




\subsection{Obtaining Bio-products from Microalgae Biomass}

Microalgae biomass after cultivation must be separated from the culture medium. Therefore removal of large water volumes may be done by one or more steps applying different physical, chemical and biological technics to perform the desired solid-liquid separation.

The commonly used collection technics include sedimentation [66], centrifugation [67], filtration [68], ultrafiltration [69], electrical methods such as electrocoagulation [70] and reverse osmosis [71], sometimes with an additional flocculation step [72] or a combination flotation with flocculation [73].

At final stage microalgae biomass obtained (drying, extraction of the bioproducts, among others) represents the major economic limitation because it is depending on high specificity condition for optimization for each desired product.

Several methods have been applied to dry microalgae such as Chlorella, Scenedesmus and Spirulina. Among the most common are spray-drying (sample spray in a chamber under a hot air stream) [74], drum-drying (transfer of heat to the sample through the inner walls of the drum cylinder) [75], lyophilization (sample freezing and removal of moisture by sublimation) [76] and sun drying [77]. Sun drying is most commonly used for biomass with low moisture content and spray drying is not economically feasible for products such as biofuels and protein. Lyophilization has been used to dry microalgae in laboratory research. However, this process is very expensive to be used on a commercial scale.

In addition to conserving the biomass, the drying aids in the cellular rupture of the microalgae for the release metabolites of interest. In some cases, solvent extraction of dry biomass has demonstrated a greater recovery of intracellular metabolites than moist biomass. An intracellular product such as oils extraction is limited by moist biomass or non cellular rupture, but they are easily extracted if the biomass is previously dried.

A variety of techniques are currently available for cell disruption that can be mechanical and non-mechanical. According to Günerken et al. [78], the mechanical technique can be through solid shear (bead milling or high speed homogenization), liquid shear (high pressure homogenization or ultrasonication), or other, like microwave or pulsed electric field, while the non-mechanical technique can be chemical or enzymatic disruption.

Microalgae cells are small, covered with a relatively thick cell wall and functional products are in globules or bound to cell membranes, making extraction of intracellular products a challenge. Cell wall structure of microalgae is complex and poorly understood [79, 80] however presents an important effect on the disruption efficiency. There are no broad studies investigating the relation between cell wall composition, and disruption efficiency energy including consumption. Thus, inter- and intra-species variations besides the cultivation conditions make predictions or extrapolations very difficult. However, calculating a universal energy consumption value for a given cell disruption method and therefore making a direct comparison of different techniques is almost impossible [78].

Despite these challenges, efficient cell disruption is an essential pretreatment step to maximize product recovery from microalgae biomass. A feasible energy-efficient cell disruption technique should be established to ensure a low operating cost, high product recovery, and high quality of the extracted products.

\subsection{Biochemistry of Microalgae}

Microalgae have cells with diverse biochemical compositions (carbohydrate, protein, lipids, fatty acids, etc.) and these compositions are related to the nature of each species of microalgae, as well as the environmental factors related to the region where the 
culture is being carried out and to culture medium used [61, 81].

Each compound synthesized by microalgae is regulated by complex metabolic mechanisms. In green microalgae, for example, the complex light collector system linked to chlorophyll and carotenoid captures solar energy in the form of photons. This energy is used by photosystem II for catalytic oxidation of water, releasing protons, electrons and $\mathrm{O}_{2}$ molecules. Electrons with low potential are transferred through the transport chain of photosynthetic electrons that lead to the reduction of ferredoxin to the formation of NADPH. An electrochemical gradient is formed due to the release of protons after the oxidation of water to the thylakoid lumen, which is used to conduct the production of ATP via ATP synthase. The photosynthetic products NADPH and ATP are the substrates for the Calvin-Benson cycle, where $\mathrm{CO}_{2}$ is attached to molecules with three carbon atoms that are assimilated into sugars, starch, lipids, or other molecules required for cell growth, multiplication and defense. On the other hand, the substrates for hydrogenase, $\mathrm{H}^{+}$and $\mathrm{e}^{-}$, are supplied both via the photosynthetic electron transport chain and through the fermentation of the stored carbohydrate (starch) [82].

Bioactive compounds from microalgal can be sourced directly from primary metabolism, or can be derived from secondary metabolism and may find applications in different fields, including the agri-horticultural sector (animal feeds and health, plant stimulants), as human food and food ingredients as well as in the nutraceutical, cosmetical, and pharmaceutical industries [83]. These microorganisms are promising because they easily react to changes in environmental conditions by modulating and modifying primary and secondary metabolism, with a direct correspondence between cell physiological state and metabolite production. For example, during blooms at sea, microalgae produce and release many metabolites, in particular toxins. They represent a chemical defense against grazers and pathogens [84]. Thus culture manipulation by adapting specific condition to cultivate can modulate their metabolism, influencing compounds of interest biosynthesis and possibly increase compounds produced. Cell culture conditions manipulation is mainly achieved by changing abiotic factors such as incubation temperature, $\mathrm{pH}$ of the medium, period of cultivation, as well as salinity, light intensity and nutrients [42].

\subsection{Microalgae as Potential Source of Preservatives}

Microalgae have been used for therapeutic purposes by a long history and more recently are the focus of a hot research topic for applications, such as the production of biofuels [85-87] or carbon-dioxide capture $[88,89]$, although they could be explored as source of inputs for food formulation. This is reinforced by considering the potential of microalgae for production and over expression of selected compounds under particular growing conditions that can be adopted on bioreactors. These organisms are commonly used as bioreactors. They possess some characteristics that make them much appreciated for industrial applications, such as the possibility of using residual nutrients or $\mathrm{CO}_{2}$ from flue vents without the need for arable land [90]. These reasons justify that microalgae have been pointed out as the focus of economically feasible biorefinery processes [91, 92].

It is important to note that these microorganisms are submitted to extreme environmental conditions and can survive to natural conditions such as light salinity, radiation, temperature or available nutrients. Their survival is determined by ability for synthesing chemical structure with special properties, called bioactive compounds. So the marine ecosystem is considered an underexplored vast source of potential bioactive compounds useful in different areas, such as pharmaceuticals, cosmetics and food science [93].

Although the commercial production of microalgae began in the 60s, with species of Chlorella and Spirulina as dietary supplements [94], only years later 
its use for human consumption was consolidated, being used as an additional source of proteins, carbohydrates, fatty acids, pigments, vitamins, among other substances [95, 96]. For example, Spirulina has well-known culture conditions and has been used in food formulations or extraction of biocomposites. Studies have shown different biological actions can be identified on components of this microalga and its antifungal and antibacterial properties have being exploited [5, 34, 97, 98].

They have been used in medicine, especially due to emerging infectious diseases, viral infections, antibiotic resistant bacteria and increased incidence of cancer and other human pathologies. The search for antioxidant compounds is the main interest, since oxidative stress is a major cause of inflammatory events implicated in a large number of diseases (e.g. cancer, diabetes, neurodegenerative and cardio-vascular diseases). As for red, green, brown and blue-green algae antioxidant activities have also been found for different cyanobacterial and microalgal species, as shown in the studies summarized below.

The whole biomass extracts from Nostoc muscorum, Spirulina platensis and Anabaena flos-aquae were used by Tantawy [99]. It was verified potential inhibition against Fusarium oxysporum and Rhizoctonia solani. Efficiency of Spirulina platensis extract against $F$. oxysporum was demonstrated by $51 \%$ inhibition of halo diameter. The microalga culture was filtered and bioactive compounds were found such as phenolic compounds, IAA (Indole-3-acetic acid) and proteolitic enzymes.

Nuño et al. [100] also used the whole biomass in their studies to verify the potential of Isochrysis galbana and Nannochloropsis oculata to mitigate diabetes. The authors verified decreased glucose, triacylglycerol and cholesterol values, higher lactic acid bacteria counts, and minor signs of intestinal inflammation.

Aqueous extracts from nine microalgae (Anabaena flous-aquae, A. oryzae, Nostoc umifusum, $N$. muscorum, Oscillatoria sp., Spirulina platensis, Phormedium fragile, Wollea saccata and Chlorella vulgaris) were used by Shanab et al. [101] to DPPH free radical-scavenging assay and capture of the cationic radical ABTS. It found the inhibitory capacity between $30 \%$ and $72 \%$ for DPPH radical and $32 \%$ and $76 \%$ for ABTS radical. Among the extracts the most efficient were from Nostoc muscorum and Oscillatoria $\mathrm{sp}$.

El-Kassas and El-Sheekh [102] used gold nanoparticles with an aqueous extract of Corallina officinalis to test the cytotoxic activity against human breast cancer (MCF-7) cell cultures. The algae extract showed potent cytotoxic activity against MCF-7 cells, causing necrosis at high concentrations while lower concentrations were without effect as indicated by DNA fragmentation assay.

The Spirulina platensis extract and purified calcium spirulan (Ca-SP) were tested about their inhibitory effects on herpes simplex virus 1 (HSV-1) by plaque reduction assay, quantitative $\mathrm{PCR}$ and confirmed in human keratinocytes. The authors verified the topical application of a cream containing the Spirulina species extract and $\mathrm{Ca}-\mathrm{SP}$ protect against herpes labialis in susceptible subjects, indicating potential clinical relevance.

Danyal et al. [103] used the Pithophora oedogonium biomass ethanolic extract for the disc-diffusion method for inhibition the growth of Salmonella I (egg), Staphylococcus sp., 4978, Fusarium solini and Penicillium viridicatum. The maximum activity was observed against $F$. solini and the ethanolic extract of $P$. oedogonium can be efficiently used in antibiotics production.

Specific immunodominant proteins from Prototheca zopfii were used by Irrgang et al. [104], the separation of proteins was realized by two-dimensional gel electrophoresis. Were identified 15 proteins including malate dehydrogenase, elongation factor 1-alpha, heat shock protein 70, and 
14-3-3 protein, which were previously described as immunogenic proteins of other eukaryotic pathogens.

Chlorophyll extract from Phormidium autumnale was tested about the peroxyl radical scavenger capacity. Was found the potent scavenger of peroxyl radical, being almost 200 times more potent than $\alpha$-tocopherol, which suggests the microalgae as potential source of bioactive tetrapyrrole compounds [105].

Total phenolic, carotenoid content and polyunsaturated fatty acids (PUFA) from Dunalliela sp., Tetraselmis sp. and Nannochloropsis gaditana were tested in DPPH free radical-scavenging assay. It was shown that microalgae extracts exerting the high antioxidant activity are potential new source of natural antioxidants [16].

Esquivel-Hernández et al. [106] used different polar solvent (PS) extracts (thiamine, riboflavin, C-phycocyanin, A-phycocyanin) and non-polar solvent (NPS) extracts ( $\alpha$-tocopherol, $\beta$-carotene and fatty acids) from Arthrospira platensis for antioxidant activity for FRAP assay; antimicrobial activity against Pseudomonas aeuginosa ATCC 27853, Staphylococcus aureus ATCC 25923, Candida albicans ATCC 10231, Escherichia coli ATCC 25922. The authors verified that the microalgae PS extracts showed high antimicrobial activity, while the NPS had higher antioxidant activity.

The carotenoids from Tertaselmis suecica, Dunaliella salina, Pavlova salina and Isochrysis galbana were used to test the oxygen radical absorvance capacity (ORAC). The authors conclude that microalgae should be further developed for commercial carotenoid production [15].

Millao and Uquiche [17] used carotenoids extracts from Nannochloropsis gaditana to test the antioxidant activity (DPPH assay and bleaching $\beta$-carotene assay) and anti-inflammatory activity (lipoxygenase inhibition). The antioxidant and anti-inflammatory activities were characterized in the selected supercritical extract, showing important bioactive properties. This extract may therefore have applications in the development of functional products.

Besides, there are a lot of studies that characterized the phenolic compounds found in microalgae biomass about different preservative properties. In addition to the antioxidant activity, some of these compounds may act as antifungal and inhibitors of mycotoxin production, such as aflatoxin. They act by regulation on lipid peroxidation, inhibiting the formation of peroxides and consequent oxidative stress that is related to biosynthesis of aflatoxins [34, 107]. There are scientific evidences that allow to associate these properties mainly to their phenolic compounds [18].

Phenolic compounds from Chlorella sp. and Spirulina platensis were applied to evaluate the effect of Rhizopus oryzae and Aspergillus flavus multiplication and antimycotoxin activity against $A$. flavus. Were observed a great capacity to inhibit formation fungi cell wall and a total inhibition of aflatoxin $\mathrm{B}_{1}$ production up to the 10th day of Aspergillus flavus cultivation [34].

Custódio et al. [108] analyzed the DPPH free radical-scavenging assay, iron and copper chelating activity and acetylcholinesterase inhibitory activity of phenolic compounds from Tetraselmis chuii, Nannochloropsis oculata, Chlorella minutissima and Rhodomonas salina. The species were a valuable source of antioxidants, metal chelators and AChE inhibitors. Bioactivities related to the other minor compounds in the samples could not be excluded.

Farvin and Jacobsen [19] evaluated antioxidant activity of phenolic compounds from 16 different microalgae (Fucus vesiculosus, F. serratus, F. distichus, F. spiralis, Saccharina latissima, Chondrus crispus, Gracilaria vermiculophyllum, Enteromorpha intestinalis, Ulva lactuca, Sargassum muticum, Dictyota dichotoma, Polysiphonia fucoides, Laminaria digitata, Palmaria palmata, M. stellatus and Porphyra purpúrea). It was carried out four in vitro antioxidant assays 
(2,2-diphenyl-1-picrylhydrazyl radical scavenging activity, reducing power, ferrous ion-chelating and liposome model system) and the lipid peroxidation inhibition in a liposomal model system. The results showed that the antioxidant assays were correlated with total phenolic content, other active compounds were co-extracted (pigments, tocopherols and sulphated polysaccharides) and in aqueous extracts soluble proteins or peptides.

Phenolic extracts from Spirulina sp. were tested about ability to inhibit Fusarium graminearum and manifestation of toxigenic potential. The results showed inhibition of $90 \%$ on isolates of the complex F. graminearum growth; production of glycosamine was reduced from $11.5 \mathrm{mg} \cdot \mathrm{g}^{-1}$ to $6.1 \mathrm{mg} \mathrm{g}^{-1}$; decrease 15- and 6-fold nivalenol and 15 acetyl deoxynivalenol production [5].

Christ et al. [97] applied phenolic compounds from Spirulina LEB-18 as preservatives in the formulation of pizza dough's. It was verified promising effect of microalgae extracts instead of chemical preservative propionate to inhibitory mold and yeast counts until 10 days after the formulation of the pizza dough.

Polyphenol extracted and obtained with solvents with different polarities (water, ethyl acetate and hexane) from Dunaliella salina, Fischerella ambigua, Nostoc muscorum, Oocystis pusilla and Scenedesmus rubescens were assessed about their antioxidant capacity. Obtained data from DPPH assay suggest that the studied microalgal cells possessed significant levels of antioxidants compounds. The authors prove that a great part of this antioxidant activity is due to its phenolic compounds, the most efficient strain ( $S$. rubescens) showed a great potential for antioxidant and polyphenolic compounds production in large scales [109].

The antifungal activity of phenolic extracts, from Spirulina LEB-18, free and encapsulation in the liposomes, against Fusarium graminearum isolates was tested by Pagnussatt et al. [110]. The results showed that the antifusarium properties of phenols are preserved after incorporation in liposomes. The highest antifungal effect was observed when $8 \%(\mathrm{v} / \mathrm{v})$ phenolic extract was encapsulated into the soybean asolectin liposome, resulting in $90 \%$ inhibition against $74 \%$ from the free extract.

The high value associated with microalgal biomass is due to the therapeutic effects of its extracts. The reducing activity of some chemical compounds alters routes of the secondary metabolism of toxigenic fungi, inhibiting the production of mycotoxins. Thus, it is fundamental to add value to biomass and develop processes for efficient cultivation recovery, identification and extraction of these compounds, establishing criteria production processes control and downstream operations, as well as the definition of parameters that allow the application of these compounds on an industrial scale.

The knowledge regard presence of substances that have antifungal activity and antimycotoxins in microalgae suggest the possibility of extract bioactive compounds and apply them as their use as a substitute for chemical preservatives. It is important that the species can be cultivated in regions where grain crop occurs in order to improve competitiveness, mitigate contamination risk by routine diet and prevent damage to the environment.

\section{Conclusion}

Besides the use to obtain energy and extraction of macromolecules destined to the formulation of fortified foods, there are evidences that microalgae biomass can be source of natural preservative compounds. Literatures have been demonstrated that these compounds have antioxidant, antimicrobial, antifungal, antiinflammatory and antitumoral capacity, and phenolic compounds represent the majority of biomolecules with functional activity against degrading process. The possibility of obtaining preservative compounds through the microalgae biomass is interesting for both the pharmaceutical and food industries, since it is possible under controlled 
conditions to improve production of compounds with bioactivity.

\section{References}

[1] Parekh, J., and Chanda, V. S. 2007. "In Vitro Antimicrobial Activity and Phytochemical Analysis of Some Indian Medicinal Plants.” Turk. J. Biol. 31: 53-8.

[2] Moreira, M. R., Ponce, A. G., Del Valle, C. E., and Roura, S. I. 2005. "Inhibitory Parameters of Essential Oils to Reduce a Foodborne Pathogen.” LWT 38 (5): 565-70.

[3] Edeoga, H. O., Okwu, D. E., and Mbaebie, B. O. 2005. "Phytochemical Constituents of Some Nigerian Medicinal Plants." Afr. J. Biotechnol. 4: 685-8.

[4] Oliveira, M. S., and Badiale-Furlong, E. 2008. "Screening of Antifungal and Antimycotoxigenic Acitivity of Plant Phenolic Extracts." World Mycotoxin J. 1 (2): 139-46.

[5] Pagnussatt, F. A., Del Ponte, E. M., Garda-Buffon, J., and Badiale-Furlong, E. 2014. "Inhibition of Fusarium Graminearum Growth and Mycotoxin Production by Phenolic Extract from Spirulina sp." Pestic Biochem Phys. 108: 21-6.

[6] Asthana, R. K., Tripathi, M. K., Srivastava, A., Singh, A. P., Singh, S. P., and Nath, G. 2009. "Isolation and Identification of a New Antibacterial Entity from the Antarctic Cyanobacterium Nostoc CCC 537.” J. Appl. Phycol. 21 (1): 81-8.

[7] Limafilho, J. V. M., Carvalho, A. F. F. U., and Freitas, S. M. 2002. "Antibacterial Activity of Extracts of Six Macro Algae from the Northeastern Brazilian Coast." Braz. J. Microbiol. 33: 311-3.

[8] Choudhary, S., Sree, A., Mukherjee, S. C., Patnaik, P., and Bapuji, M. 2005. "In Vitro Antibacterial Activity of Extracts of Selected Marine Algae and Mangroves against Fish Pathogens.” Asian Fish Sci. 18: 285-94.

[9] Desbois, A. P., Lebl, T., Yan, L., and Smith, V. J. 2008. "Isolation and Structural Characterisation of Two Antibacterial Free Fatty Acids from the Marine Diatom, Phaeodactylum tricornutum." Appl. Microbiol. Biotechnol. 81 (4): 755-64.

[10] Correa, M. G., Bidone, J., Baisch, A. L. M., Dora, C. L., Badiale-Furlong, E., Costa, J. A. V., and Giroldo, D. 2016. Processo de Extração de Compostos Fenólicos A Partir Da Microalga Pediastrum boryanum. Brasil.

[11] Dors, G. C., Primel, E. G., Fagundes, C. A., Mariot, C. H. P., and Badiale-Furlong, E. 2011. "Distribution of Pesticides in Rice Grain and Rice Bran." J. Braz. Chem. Soc. 22: 1921-30.

[12] Heidtmann-Bemvenuti, R., Mendes, G. R. L., Scaglioni, P. T., Furlong, E. B., and Soares, L. A. S. 2012. "Biochemistry and Metabolism of Mycotoxins-A
Review.” Afr. J. Food Sci. 5: 861-9.

[13] Viuda-Martos, Y., Navajas-Ruiz, Y., Fernandez-Lopes, J., and Perez-Alvarez, J. 2008. "Antifungal Activity of Lemon (Citrus Lemon L.), Mandarin (Citrus Reticulata L.), Grapefruit (Citrus Paradisi L.) and Orange (Citrus Sinensis L.) Essential Oils." Food Control 19: 1130-8.

[14] Mimouni, V., Ulmann, L., Pasquet, V., Mathieu, M., Picot, L., Bougaran, G., Cadoret, J. P., Morant-Manceau, A., and Schoefs, B. 2012. "The Potential of Microalgae for the Production of Bioactive Molecules of Pharmaceutical Interest." Curr. Pharm. Biotechnol. 13: 2733-50.

[15] Faruq, A., Kent, F., Michael, N., Warwick, T., Yan, L., and Peer, M. S. 2014. "Profiling of Carotenoids and Antioxidant Capacity in Microalgae from Subtropical Coastal and Brackish Waters." Food Chem. 165: 300-6.

[16] Maadane, A., Merghoub, N., Ainane, T., El-Arroussi, H., Nenhima, R., Amzazi, S., Bakri, Y., and Wahby, I. 2015. "Antioxidant Activity of Some Moroccan Marine Microalgae: Pufa Profiles, Carotenoids and Phenolic Content." J. Biotechnol. 215: 13-9.

[17] Millao, S., and Uquiche, E. 2016. "Antioxidant Activity of Supercritical Extracts from Nannochloropsis gaditana: Correlation with Its Content of Carotenoids and Tocopherols.” J. Supercrit Fluids 111: 143-50.

[18] Kaur, C., and Kapoor, H. C. 2002. "Anti-oxidant Activity and Total Phenolic Content of Some Asian Vegetables." Int. J. Food Sci. Tech. 37: 153-61

[19] Farvin, K. H. S., and Jacobsen, C. 2013. "Phenolic Compounds and Antioxidant Activities of Selected Species of Seaweeds from Danish Coast." Food Chem. 138: $1670-81$.

[20] Tiwari, B. K., Valdramidis, V. P., O'Donnell, C. P., Muthukumarappan, K., Bourke, P., and Cullen, P. J. 2009. "Application of Natural Antimicrobials for Food Preservation.” J. Agr. Food Chem. 57: 5987-6000.

[21] Kumari, S., and Kondapi, A. K. 2017. "Lactoferrin Nanoparticle Mediated Targeted Delivery of 5-fluorouracil for Enhanced Therapeutic Efficacy." Int. J. Biol. Macromol. 95: 232-7.

[22] Castro, R. J. S., and Sato, H. H. 2015. "Biologically Active Peptides: Processes for Their Generation, Purification and Identification and Applications as Natural Additives in the Food and Pharmaceutical Industries." Food Res. Int. 74: 185-98.

[23] Moreno-Vásquez, M. J., Valenzuela-Buitimea, E. L., Plascencia-Jatomea, M., Encinas-Encinas, J. C., Rodríguez-Félix, F., Sánches-Valdes, S., Rosas-Burgos, E. C., Ocaño-Higuera, V. M., and Graciano-Verdugo, A. Z. 2017. "Functionalization of Chitosan by a Free Radical Reaction: Characterization, Antioxidant and Antibacterial Potential." Carbohydr. Polym. 155: 117-27. 
[24] Yoshida, K., Mukai, Y., Niidome, T., Takashi, C., Tokunaga, Y., Hatakeyama, T., and Aoyagi, H. 2001. "Interaction of Pleurocidin and Its Analogues with Phospholipid Membrane and Their Antimicrobial Activity.” J. Pept. Res. 57: 119-26.

[25] Bajpai, V. K., Rahman, A., and Kang, S. C. 2008. "Chemical Composition and Inhibitory Parameters of Essential Oil and Extracts of Nandina Domestica Thunb. to Control Food-Borne Pathogenic and Spoilage." Int. J. Food Microbiol. 125: 117-22.

[26] Bordin, K., Saladino, F., Fernández-Blanco, C., Ruiz, M. J., Mañes, J., Fernández-Franzón, M., Meca, G., and Luciano, F. B. 2017. "Reaction of Zearalenone and $\alpha$-zearalenol with Allyl Isothiocyanate, Characterization of Reaction Products, Their Bioaccessibility and Bioavailability in vitro." Food Chem. 15: 648-54.

[27] Ahmad, V., Khan, M. S., Jamal, Q. M. S., Alzohairy, M. A., Al Karaawi, M. A., and Siddiqui, M. U. 2017. "Antimicrobial Potential of Bacteriocins: In Therapy, Agriculture and Food Preservation." Int. J. Antimicrob Agents 49 (1): 1-11.

[28] Khan, H., Flint, S., and Yu, P. 2010. "Enterocins in Food Preservation.” Int. J. Food Microbiol. 141: 1-10.

[29] Deegan, L. H., Cotter, P. D., Hill, C., and Ross, P. 2006. "Bacteriocins: Biological Tools for Biopreservation and Shelf-life Extension.” Int. Dairy J. 16: 1058-71.

[30] Settanni, L., and Corsetti, A. 2008. "Application of Bacteriocins in Vegetable Food Biopreservation." Int. J. Food Microbiol. 121: 123-38.

[31] Hu, Y., Wu, T., Wu, C., Fu, S., Yuan, C., and Chen, S. 2017. "Formation and Optimization of Chitosan-Nisin Microcapsules and Its Characterization for Antibacterial Activity." Food Control. 72 (A): 43-52.

[32] Espitia, P. J. P., Otoni, C. G., and Soares, N. F. F. 2016. "Pediocin Applications in Antimicrobial Food Packaging Systems." Antimicrob Food Pack 445-54.

[33] Arqués, J. L., Rodríguez, E., Nuñez, M., and Medina, M. 2011. "Combined Effect of Reuterin and Lactic Acid Bacteria Bacteriocins on the Inactivation of Food-Borne Pathogens in Milk." Food Control. 22: 457-61.

[34] Souza, M. M., Prietto, L, Ribeiro, A. C., Souza, T. D., and Badiale-Furlong, E. 2011. "Assessment of the Antifungal Activity of Spirulina Platensis Phenolic Extract against Aspergillus Flavus." Ciênc Agrotec. 35 (6): 1050-8.

[35] Pagnussatt, F. A., Kupski, L., Darley, F. T., Filoda, P. F., Del Ponte, E. M., Garda-Buffon, J., and Badiale-Furlong, E. 2013. "Fusarium graminearum Growth Inhibition Mechanism Using Phenolic Compounds from Spirulina sp." Ciênc. Tecnol. Aliment 33 (1): 75-80.

[36] Marino, M., Bersani, C., and Comi. G. 2001. "Impedance Measurements to Study the Antimicrobial Activity of
Essential Oils from Lamiaceae and Compositae." Int. J. Food Microbiol. 67: 187-95.

[37] Saravanakumar, K., Yu, C., Dou, K., Wang, M., Li, Y., and Chen, J. 2016. "Synergistic Effect of Trichoderma-derived Antifungal Metabolites and Cell Wall Degrading Enzymes on Enhanced Biocontrol of Fusarium oxysporum f. sp. cucumerinum." Biol. Control. 94: 37-46.

[38] Aidoo, K. E., Hendry, R., and Wood, B. J. 1981. "Estimation of Fungal Growth in a Solid State Fermentation System." Appl. Microbiol. Biotechnol. 12: 6-9.

[39] Tian, J., Huang, B., Luo, X., Zeng, H., Ban, X., He, J., and Wang, Y. 2012. "The Control of Aspergillus flavus with Cinnamomum jensenianum Hand.-Mazz Essential Oil and Its Potential Use as a Food Preservative." Food Chem. 130 (3): 520-7.

[40] Madonna, A. J., Voorhees, K. J., and Hadfield, T. L. 2001. "Rapid Detection of Taxonomically Important Fatty Acid Methyl Ester and Steroid Biomarkers Using in Situ Thermal Hydrolysis/Methylation Mass Spectrometry (THM-MS): Implications for Bioaerosol Detection." J. Anal. Appl. Pyrol. 61: 65-89.

[41] Joint, I., Mühling, M., and Querellou, J. 2010. "Culturing Marine Bacteriae an Essential Prerequisite for Biodiscovery." Microb. Biotechnol. 3: 564-75.

[42] De Morais, M. G., Vaz Bda, S., de Morais, E. G., and Costa, J. A. V. 2015. "Biologically Active Metabolites Synthesized by Microalgae.” Bio. Med. Res. Int. Article ID 835761: 15 .

[43] Ely, R., Supriya, T., and Naik, C. G. 2004. "Antimicrobial Activity of Marine Organisms Collected off the Coast of South East India." J. Exp. Mar. Biol. Ecol. 309: 121-7.

[44] Hannon, M., Gimpel, J., Tran, M., Rasala, B., and Mayfield, S. 2010. "Biofuels from Algae: Challenges and Potential." Biofuels 1 (5): 763-84.

[45] Ugwu, C. U., Aoyagi, H., and Uchiyama, H. 2008. "Photobioreactors for Mass Cultivation of Algae." Bioresource Technol. 99 (10): 4021-8.

[46] Mata, T. M., Martins, A. A., and Caetano, N. S. 2010. "Microalgae for Biodiesel Production and Other Applications: A Review." Renew Sust Energ Rev. 14: 217-32.

[47] Enzing, C., Ploeg, M., Barbosa, M., and Sijtsma, L. 2014. "Microalgae-based Products for the Food and Feed Sector: An Outlook for Europe." JRC Scientific and Policy Reports, European Commission.

[48] Singh, S. P., and Singh, P. 2014. "Effect of $\mathrm{CO}_{2}$ Concentration on Algal Growth: A Review." Renew Sust Energ Rev. 3: 8172-9.

[49] Davis, R., Aden, A., and Pienkos, P. T. 2011. 
"Techno-economic Analysis of Autotrophic Microalgae for Fuel Production.” Appl. Energy 88 (10): 3524-31.

[50] Mohan, S. V., Rohit, M. V., Chiranjeevi, P., Chandra, R., and Navaneeth, B. 2015. "Heterotrophic Microalgae Cultivation to Synergize Biodiesel Production with Waste Remediation: Progress and Perspectives." Bioresource Technol. 184: 169-78.

[51] Deschênes, J. S., Boudreau, A., and Tremblay, R. 2015. "Mixotrophic Production of Microalgae in Pilot-scale Photobioreactors: Practicability and Process Considerations.” Algal. Res. 10: 80-6.

[52] Selvakumar, P., and Umadevi, K. 2014. "Enhanced Lipid and Fatty Acid Content under Photoheterotrophic Condition in the Mass Cultures of Tetraselmis gracilis and Platymonas convolutae." Algal. Res. 6: 180-5.

[53] Dasgupta, C. N., Gilbert, J. J., Lindblad, P., Heidorn, T., Borgvang, S. A., Skjanes, K., and Das, D. 2010. "Recent Trends on the Development of Photobiological Processes and Photobioreactors for the Improvement of Hydrogen Production.” Int. J. Hydrogen Energy 35: 10218-38.

[54] Brennan, L., and Owende, P. 2010. "Biofuels from Microalgae-A Review of Technologies for Production, Processing, and Extrations of Biofuels and Co-products." Renew Sust Energ Rev. 14: 557-77.

[55] Chinnasamy, S., Bhatnagar, A., Hunt, R. W., and Das, K. C. 2010. "Microalgae Cultivation in a Wastewater Dominated by Carpet Mill Effluents for Biodiesel Applications.” Bioresour Technol. 101: 3097-105.

[56] Jiang, L., Luo, S., Fan, X., Yang, Z., and Guo, R. 2011. "Biomass and Lipid Production of Marine Microalgae Using Municipal Wastewater and High Concentration of $\mathrm{CO}_{2}$." Appl. Energ. 88: 3336-41.

[57] Noaman, M. N. 2004. "Effect of Potassium and Nitrogen Fertilizers on the Growth and Biomass of Some Halophytes Grown under High Levels of Salinity." J. Agron. 3: 25-30.

[58] Scherholz, M. L., and Curtis, W. R. 2013. "Achieving pH Control in Microalgal Cultures through Fed-batch Addition of Stoichiometrically-balanced Growth Media." BMC Biotechnol. 13: 39.

[59] Aburai, N., Sumida, D., and Abe, K. 2015. "Effect of Light Level and Salinity on the Composition and Accumulation of Free and Ester-type Carotenoids in the Aerial Microalga Scenedesmus sp. (Chlorophyceae)." Algal. Res. 8: 30-6.

[60] Baicha, Z., Salar-García, M. J., Ortiz-Martínez, V. M., Hernández-Fernández, F. J., de los Ríos, A. P., Labjar, N., Lotfi, E., and Elmahi, M. A. 2016. "Critical Review on Microalgae as an Alternative Source for Bioenergy Production: A Promising Low Cost Substrate for Microbial Fuel Cells." Fuel Process Technol. 154: 104-16.
[61] Miao, X., and Wu, Q. 2006. "Biodiesel Production from Heterotrophic Microalgal Oil.” Bioresource Technol. 97: 841-6.

[62] Sompech, K., Chisti, Y., and Srinophakun, T. 2012. "Design of Aceway Ponds for Producing Microalgae." Biofuels 3 (4): 387-97.

[63] Gouveia, L., Neves. C., Sebastião, D., Nobre, B. P., and Matos. 2014. "Effect of Light on the Production of Bioelectricity and Added-Value Microalgae Biomass in a Photosynthetic Alga Microbial Fuel Cell.” Bioresour Technol. 154: 171-7.

[64] Li, J., Stamato, M., EVelliou, E., Jeffryes, C., and Agathos, S. N. 2015. "Design and Characterization of A Scalable Airlift Flat Panel Photobioreactor for Microalgae Cultivation.” J. Appl. Phycol. 27: 75-86.

[65] Perez-Garcia, O., Escalante, F. M. E, de-Bashan, L. E., and Bashan, Y. 2011. "Heterotrophic Cultures of Microalgae, Metabolism and Potential Products." Water Res. 45: 11-36.

[66] Vandamme, D., Foubert, I., and Muylaert, K. 2013. "Flocculation as a Low-cost Method for Harvesting Microalgae for Bulk Biomass Production." Trends Biotechnol. 31: 233-9.

[67] Gerardo, M. L., Van Den Hende, S., Vervaeren, H., Coward, T., and Skill, S. C. 2015. "Harvesting of Microalgae within a Biorefinery Approach: A Review of the Developments and Case Studies from Pilot-plants." Algal Res. 11: 248-62.

[68] Danquah, M. K., Ang, L., Uduman, N., Moheimani, N., and Forde, G. M. 2009. "Dewatering of Microalgal Culture for Biodiesel Production: Exploring Polymer Flocculation and Tangential Flow Filtration.” J. Chem. Technol. Biotechnol. 84: 1078-83.

[69] Mo, W., Soh, L, Werber, J. R., Elimelech, M, and Zimmerman, J. B. 2015. "Application of Membrane Dewatering for Algal Biofuel.” Algal Res. 11: 1-12.

[70] Lee, A. K., Lewis, D. M., and Ashman, P. J. 2013. "Harvesting of Marine Microalgae by Electroflocculation: the Energetics, Plant Design, and Economics." Appl. Energy 108: 45-53.

[71] Mazzuca-Sobczuk, T., Ibáñez-González, M. J., Molina-Grima, E., and Chisti, Y. 2015. "Forward Osmosis with Waste Glycerol for Concentrating Microalgae Slurries.” Algal Res. 8: 168-73.

[72] Chatsungnoen, T., and Chisti, Y. 2016. "Harvesting Microalgae by Flocculation-Sedimentation." Algal Res. 13: 271-83.

[73] Laamanen, C. A., Senhorinho, G. N. A., Ross, G. M., and Scott, J. Á. 2016. "Heat-aided Flocculation for Flotation Harvesting of Microlagae.” Algal Res. 20: 213-7.

[74] Arney, B., Liu, W., Forster, I. P., McKinley, R. S., and Pearce, C. M. 2015. "Feasibility of Dietary Substitution 
of Live Microalgae with Spray-dried Schizochytrium sp. or Spirulina in the Hatchery Culture of Juveniles of the Pacific Geoduck Clam (Panopea generosa).” Aquaculture 444 (1): 117-33.

[75] Gudin, C., and Chaumont, D. 1991. "Cell Fragility, the Key Problem of Microalgae Mass Production in Closed Photobioreactors." Bioresour Technol. 38: 141-51.

[76] Silva, A. P. F. S., Carantino Costa, M., Colzi Lopes, A., Abdala Neto, E. F., Carrhá Leitão, R., Rossas Mota, C., and Bezerra dos Santos, A. A. 2014. "Comparison of Pretreatment Methods for Total Lipids Extraction from Mixed Microalgae Renew.” Energy 63: 762-6.

[77] Balasubramanian, R. K., Doan, T. T., and Obbard, J. P. "Factors Affecting Cellular Lipid Extraction from Marine Microalgae." Chem. Eng. J. 215: 929-36.

[78] Günerken, E, D’Hondt, E., Eppink, M. H. M., Garcia-Gonzalez, L., Elst, K., and Wiljffels, R. H. 2015. "Cell Disruption for Microalgae Biorefineries." Biotechnol Adv. 33: 243-60.

[79] Gerken, H. G., Donohoe, B., and Knoshaug, E. P. 2013. "Enzymatic Cellwall Degradation of Chlorella vulgaris and Other Microalgae for Biofuels Production." Planta 237 (1): 239-53.

[80] Scholz, M. J., Weis, T. L., Jinkerson, R. E., Jing, J., Roth, R., and Goodenough, U. 2014. "Ultrastructure and Composition of the Nannochloropsis gaditana Cell Wall." Eukaryot Cell 13 (11): 1450-64.

[81] Zamalloa, C., Vulsteke, E., Albrecht, J., and Verstraete, W. 2011. "The Techno-economic Potential of Renewable Energy through the Anaerobic Digestion of Microalgae." Bioresource Technol. 102: 1149-58.

[82] Beer, L. L., Boyd, E. S., Peters, J. W., and Posewitz, M. C. 2009. "Engineering Algae for Biohydrogen and Biofuel Production." Curr. Opin. Biotech. 20: 264-71.

[83] Stengel, D. B., and Connan, S. 2015. "Marine Algae: A Source of Biomass for Biotechnological Applications." Methods Mol. Biol. 1308: 1-37.

[84] Ribalet, F., Wichard, T., Pohnert, G., Ianora, A., Miralto, A., and Casotti, R. 2007. "Age and Nutrient Limitation Enhance Polyunsaturated Aldehyde Production in Marine Diatoms." Phytochemistry 68: 2059-67.

[85] Dutta, S., Neto, F., and Coelho, M. C. 2016. "Microalgae Biofuels: A Comparative Study on Techno-economic Analysis \& Life-cycle assessment.” Algal Res. 20: 44-52.

[86] Hallenbeck, P. C., Mraz, M. G. M., and Veverka, D. 2016. "Solar Biofuels Production with Microalgae." Appl. Energy 179: 136-45.

[87] Milano, J., Ong, H. C., Masjuki, H. H., Chong, W. T., Lam, M. K., Loh, P. K., and Vellayan, V. 2016. "Microalgae Biofuels as an Alternative to Fossil Fuel for Power Generation." Renew Sust Energ Rev. 58: 180-97.

[88] Bilanovic, D., Holland, M., Starosvetsky, J., and Armon,
R. 2016. "Co-cultivation of Microalgae and Nitrifiers for Higher Biomass Production and Better Carbon Capture." Bioresource Technol. 220: 282-8.

[89] Thawechai, T., Cheirsilp, B., Louhasakul, Y., Boonsawang, P., and Prasertsan, P. 2016. "Mitigation of Carbon Dioxide by Oleaginous Microalgae for Lipids and Pigments Production: Effect of Light Illumination and Carbon Dioxide Feeding Strategies." Bioresource Technol. 219: 139-49.

[90] Herrero, M., and Ibáñez, E. 2015. "Green Processes and Sustainability: An Overview on the Extraction of High Added-value Products from Seaweeds and Microalgae." J. Supercrit Fluids 96: 211-6.

[91] Da Silva, T. L., Gouveia, L., and Reis, A. 2014. "Integrated Microbial Processes for Biofuels and High Value-added Products: the Way to Improve the Cost Effectiveness of Biofuel Production." Appl. Microbiol. Biotechnol. 98: 1043-53.

[92] Hariskos, I., and Posten, C. 2014. "Biorefinery of Microalgae-opportunities and Constraints for Different Production Scenarios.” Biotechnol. J. 9: 739-52.

[93] Hernandez-Ledesma, B., and Herrero, M. 2014. Bioactive Compounds from Marine Foods. Chichester-UK: Wiley Blackwell.

[94] Beneman, J. R. 1990. "Microalgae Products and Production: An Overview." J. Ind. Microbiol. Biotechnol. 31 (5): 247-56.

[95] Torre, P., Sato, S., Gioielli, L. A., Sassano, C. E. N., Carvalho, J. C. M., and Converti, A. 2003. "Fed-batch Addition of Urea for Spirulina platensis Cultivation." Enzyme Microb. Technol. 33: 698-707.

[96] Ferreira, L. S., Rodrigues, M. S., Converti, A., Sato, S., and Carvalho, J. C. M. 2012. "Kinetic and Growth Parameters of Arthrospira (Spirulina) platensis Cultivated in Tubular Photobioreactor under Different Cell Circulation Systems.” Biotechnol. Bioeng 109: 444-50.

[97] Christ-Ribeiro, A., Bretanha, C. C., Giacobbo, G., De Souza, M. M., and Badiale-Furlong, E. 2016. "Compostos fenólicos extraídos de fontes naturais aplicados como conservadores em massas de pizza." Rev. Ciên. Inov. 1 (1).

[98] Mader, J., Gallo, A., Schommartz, T., Handke, W., Nagel, C. H., Günther, P., Brune, W., and Reich, K. 2016. "Calcium Spirulan Derived from Spirulina platensis Inhibits Herpes Simplex Virus 1 Attachment to Human Keratinocytes and Protects against Herpes Labialis." $J$. Allergy Clin. Immunol. 137 (1): 197-203.

[99] Tantawy, S. T. A. 2011. "Biological Potential of Cyanobacteria Metabolites against Some Soil Pathogenic Fungi." JFAE 9 (1): 663-6.

[100] Nuño, K., Villarruel-López, A., Puebla-Pérez, A. M., Romero-Velarde, E., Puebla-Mora, A. G., and Ascencio, F. 2013. "Effects of the Marine Microalgae Isochrysis 
galbana and Nannochloropsis oculata in Diabetic Rats." J. Funct. Foods 5: 106-15.

[101] Shanab, S. M. M., Mostafa S. S. M, Shalaby, E. A., and Mahmoud, G. I. 2012. "Aqueous Extracts of Microalgae Exhibit Antioxidant and Anticancer Activities." Asian Pac. J. Trop. Biomed. 2 (8): 608-15.

[102] El-Kassas, H. Y., and El-Sheekh, M. M. 2014. "Cytotoxic Activity of Biosynthesized Gold Nanoparticles with an Extract of the Red Seaweed Corallina Officinalis on the MCF-7 Human Breast Cancer Cell Line." Asian Pac. J. Cancer Prev. 15 (10): 4311-7.

[103] Danyal, A., Mubeen, U., and Malik, K. A. 2013. "Investigating Two Native Algal Species to Determine Antibiotic Susceptibility against Some Pathogens." Curr. Res. J. Biol. Sci. 5: 70-4.

[104] Irrgang, A., Weise, C., Murugaiyan, J., and Roesler, U. 2015. "Identification of Immunodominant Proteins of the Microalgae Prototheca by Proteomic Analysis." New Microbes New Infect 3: 37-40.

[105] Fernandes, A. S., Nogara, G. P., Menezes, C. R., Cichoski, A. J., Mercadante A. Z., Jacob-Lopes, E., and Zepka, L. Q. 2016. "Identification of Chlorophyll Molecules with Peroxyl Radical Scavenger Capacity in Microalgae Phormidium autumnale Using Ultrasound-assisted Extraction.” Food Res Int. ( in press)

[106] Esquivel-Hernández, D. A., Rodríguez-Rodríguez, J.,
Rostro-Alanis, M., Cuéllar-Bermúdez, S. P., Marcera-Andrade, E. I., Núñez-Echevarría, J. E., García-Pérez, J. S., Chandra, R., and Parra-Saldívar, R. 2017. "Advancement of Green Process through Microwave-assisted Extraction of Bioactive Metabolites from Arthrospira Platensis and Bioactivity Evaluation." Bioresource Technol. 224: 618-29.

[107] Rasooli, I., and Abyaneh, M. R. 2004. "Inhibitory Effects of Thyme Oils on Growth and Aflatoxin Production by Aspergillus Parasiticus." Food Control. 15 (6): 479-83.

[108] Custódio, L., Justo, T., Silvestre, L., Barradas, A., Duarte, C. V., Pereira, H., Barreira, L., Rauter, A. P., Alberício, F., and Varela, J. 2012. "Microalgae of Different Phyla Display Antioxidant, Metal Chelating and Acetylcholimesterase Inhitory Activites." Food Chem. 131: 134-40.

[109] Morowvat, M. H., and Ghasemi, Y. 2016. "Evaluation of Antioxidant Properties of Some Naturally Isolated Microalgae: Identification and Characterization of the Most Efficient Strain.” Biocatal. Agric. Biotechnol 8: 263-9.

[110] Pagnussatt, F. A., De Lima, V. R., Dora, C. L., Costa, J. A. V, Putaux, J. L., and Badiale-Furlong, E. 2016. "Assessment of the Encapsulation Effect of Phenolic Compounds from Spirulina sp. LEB-18 on Their Aintifusarium Activities." Food Chem. 211: 616-23. 